\title{
Dextral and sinistral Amphidromus inversus (Gastropoda: Pulmonata: Camaenidae) produce dextral sperm
}

\author{
Menno Schilthuizen • Bertie-Joan van Heuven
}

Received: 4 April 2011/Revised: 30 September 2011/Accepted: 3 October 2011/Published online: 19 October 2011

(C) The Author(s) 2011. This article is published with open access at Springerlink.com

\begin{abstract}
Coiling direction in pulmonate gastropods is determined by a single gene via a maternal effect, which causes cytoskeletal dynamics in the early embryo of dextral gastropods to be the mirror image of the same in sinistral ones. We note that pulmonate gastropod spermatids also go through a helical twisting during their maturation. Moreover, we suspect that the coiling direction of the helical elements of the spermatozoa may affect their behaviour in the female reproductive tract, giving rise to the possibility that sperm chirality plays a role in the maintenance of wholebody chiral dimorphism in the tropical arboreal gastropod Amphidromus inversus (Müller, 1774). For these reasons, we investigated whether there is a relationship between a gastropod's body chirality and the chirality of the spermatozoa it produces. We found that spermatozoa in A. inversus are always dextrally coiled, regardless of the coiling direction of the animal itself. However, a partial review of the literature on sperm morphology in the Pulmonata revealed that chiral dimorphism does exist in certain species, apparently without any relationship with the coiling direction of the body. Though our study shows that body and sperm chirality follows independent developmental pathways, it gives rise to several questions that may be relevant to the understanding of the chirality of spermatid ultrastructure and spermatozoan motility and sexual selection.
\end{abstract}

Keywords Chirality $\cdot$ Mollusca $\cdot$ Left-right asymmetry · Ultrastructural polarity $\cdot$ Maternal effect genes

Communicated by T. Bartolomaeus.

M. Schilthuizen $(\bowtie) \cdot$ B.-J. van Heuven

Netherlands Centre for Biodiversity Naturalis, P.O. Box 9517,

2300 RA Leiden, The Netherlands

e-mail: menno.schilthuizen@ncbnaturalis.nl

\section{Introduction}

Left-right patterning and the direction of chirality are often considered to be among the few developmental systems that are taxonomically sufficiently widespread to be studied in a meaningfully comparative way in almost all Bilateria. Palmer (2004), for example, mapped the evolutionary transitions among symmetry, directional asymmetry (in which within a species only one of the two possible chiral states occurs) and anti-symmetry (in which within a species the direction of chirality is random) on phylogenies for a large number of animal taxa. He found that directional asymmetry, in which the direction of chirality is almost always genetically determined, evolves directly from bilateral symmetry as frequently as via an intermediate antisymmetric state, in which the direction of chirality is almost always random, non-genetically determined.

The genes responsible for symmetry breaking have been identified in a few instances. In deuterostomes, nodal and its target gene Pitx are asymmetrically expressed in the embryo. In Mammalia, the exact manner in which developmental inequality among left and right are set up by the fluid dynamics of the gene products have been elucidated (Hirokawa et al. 2006). In Gastropoda, nodal and Pitx were recently shown to play an important role as well. In these animals which, due to torsion and coiling early in development, show very conspicuous whole-body asymmetry, nodal and Pitx are expressed asymmetrically in the early and late trochophore larva, respectively (Grande and Patel 2008).

However, it has been known for a long time that other asymmetry-determining genes are acting upstream in gastropods. Already in the early days of Mendelism, gastropod coiling direction was found to be determined by a single locus with delayed maternal inheritance (Boycott and Diver 1923; Sturtevant 1923). This means that the chirality 
of all offspring are determined by the mother's genotype, with one allele (either for dextral or for sinistral) being dominant (Schilthuizen and Davison 2005). In Lymnaea stagnalis (Linnaeus, 1758), the effect of this-yet unidentified (Harada et al. 2004) - gene is visible in the 8-cell stage, where cytoskeletal dynamics and blastomere arrangement start to deviate from symmetry and do so in opposite directions in offspring from mothers carrying dextral versus sinistral genotypes. There is, however, a delay in asymmetry onset in sinistrals compared to dextrals (Shibazaki et al. 2004). Recently, it was found that such genetically determined gastropod chirality (including the downstream nodal expression patterns) can be reversed phenotypically by experimentally rotating embryonic cells in the opposite direction (Kuroda et al. 2009).

Because mating behaviour and reproductive anatomy in terrestrial gastropods are highly asymmetric, opposite dextral and sinistral morphs usually are prevented from interchiral mating (Gittenberger 1988), leading to chiral monomorphism (directional asymmetry) in this group (Schilthuizen and Davison 2005; Ueshima and Asami 2003). One exception to this rule was recently highlighted: almost all of the over 35 species of the subgenus Amphidromus Albers, 1850 are chirally dimorphic, with dextrals and sinistrals mixed in similar proportions in a population (Fig. 1). It was discovered (Schilthuizen et al. 2007) that this genetic anti-symmetry or chiral dimorphism could be maintained by sexual selection: improved sperm transfer in interchiral copulation (due to a better match between a dextral spermatophore and a sinistral oviduct or vice versa; Fig. 2b-d) would have selected for a preference for mating with partners of opposite coiling direction. Until now, however, it has not been clear whether the sperm cells themselves [which are, in Pulmonata, strongly asymmetrically shaped (Healy 1988); see further in Results and

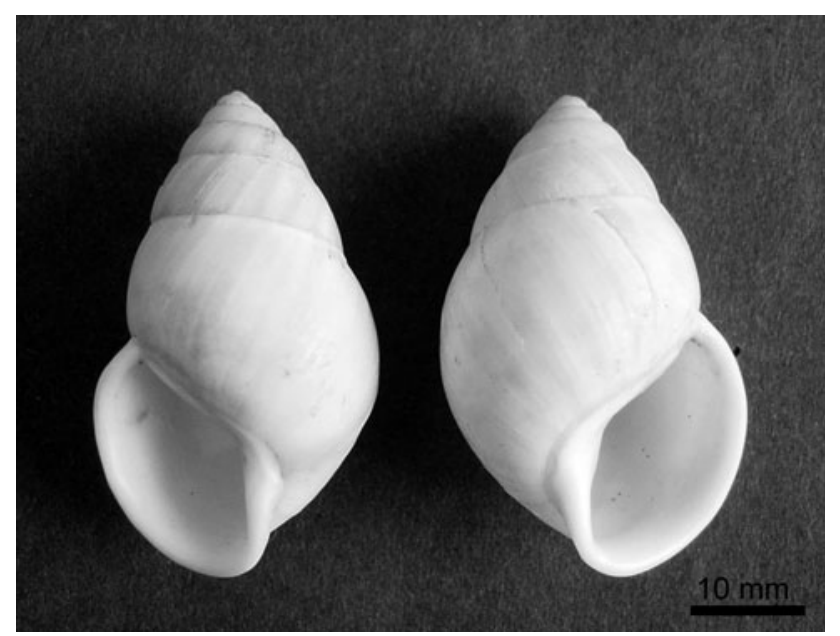

Fig. 1 Amphidromus inversus. Sinistral (left) and dextral (right) shell

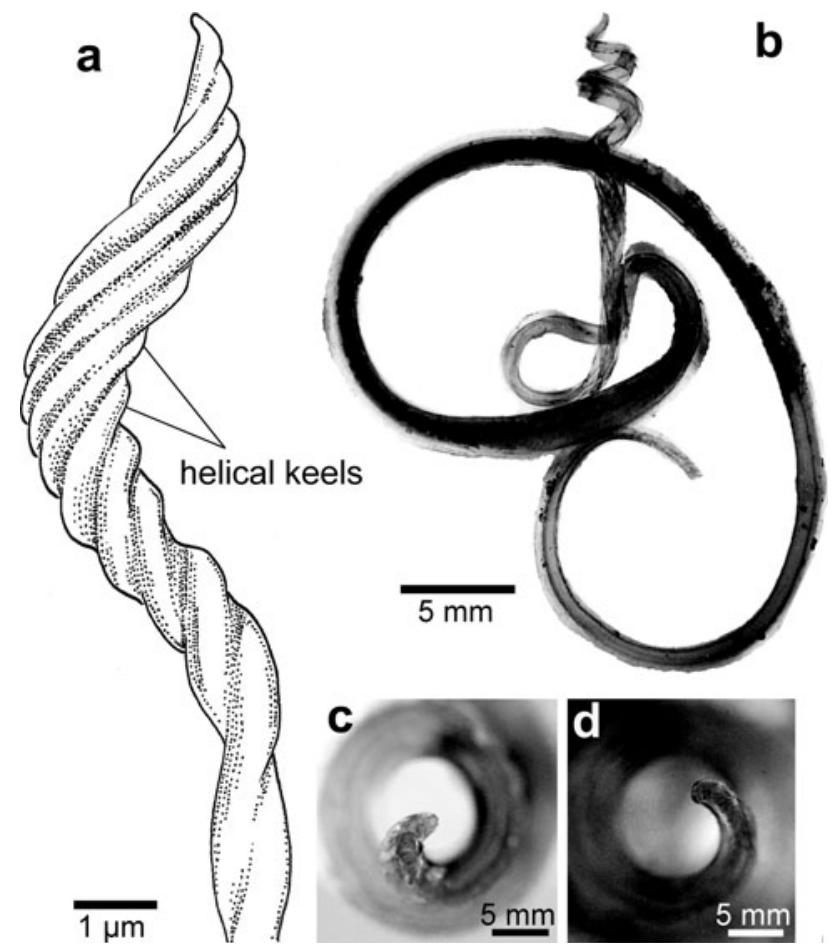

Fig. 2 Amphidromus inversus, spermatozoon and spermatophore. a Nucleus and anterior part of the midpiece (drawn after a scanning electron micrograph), showing the dextral helical elements (all studied spermatozoa, both from dextral-bodied and sinistral-bodied animals, have dextral chirality); b spermatophore with sinistrallycoiled 'corkscrew' tip, produced by a sinistral individual; $\mathbf{c}-\mathbf{d}$ tip of a sinistral (c) and dextral (d) spermatophore, in apical view

Discussion] are chirally dimorphic as well. This is, however, not impossible; although studies in chirally dimorphic Radix labiata (Rossmässler, 1835) failed to find more than one chiral morph (Selman and Waddington 1953), other studies of pulmonate sperm morphology have found that both dextral and sinistral sperm morphs exist within a species, though it remains unclear whether correlations with shell coiling direction exist (see 'Discussion' for more details on this).

In this article, we study the morphology of sperm cells in dextral and sinistral individuals of Amphidromus inversus (Müller, 1774), for two reasons. First, the fact that maternally inherited cytoskeletal dynamics are mirror imaged in the blastomeres in gastropods suggests that a chiral molecule in the egg (the hypothesized ' $F$ molecule' of Brown and Wolpert 1990) triggers chiral development. Hence, this chiral dimorphism may exist in sperm cells as well (and consequently aid in the discovery of the gene responsible). Second, swimming and turning behaviour of sperm cells may be influenced by the sperm morphology and the chirality of the travelling waves in the flagellum (Ishijima and Hamaguchi 1993; Ishijima et al. 1999), and it is conceivable that dextral sperm cells will be better able to navigate a 
sinistral oviduct and vice versa, thus contributing to increased interchiral fertilization success. To avoid confusion between the chirality of the animal and its spermatozoa, we will indicate the whole-body chirality with 'dextralbodied' or 'sinistral-bodied' thoughout this article.

\section{Materials and methods}

As described earlier (Schilthuizen et al. 2007; Schilthuizen and Looijestijn 2009), we obtained entire spermatophores from copulating Amphidromus inversus (Gastropoda Pulmonata: Camaenidae) in the field on the island of Kapas, Malaysia. These are simultaneous hermaphrodites and produce, during a lengthy copulation, a single, large spermatophore in their male genitalia, which is then transferred to the partner's female genitalia. This takes place reciprocally. We fixed copulating pairs in the field and maintained them in $70 \%$ ethanol until further study. Altogether, we had access to spermatophores produced by 6 dextral-bodied and 9 sinistral-bodied individuals. In some cases (where copulation had been interrupted early), the spermatophore was taken from the male genitalia of the sperm donor. In other cases, later in the copulation, the spermatophore was retrieved from the female genitalia of the sperm receiver. Since the spermatophore is coiled in the same direction as the animal that produces it (Schilthuizen et al. 2007), we could always confirm that a spermatophore in the female genitalia had the same chirality as the presumed sperm donor. We then used a scalpel to open each spermatophore and produce several fragments for which the spermatozoa containing content was exposed. These fragments were then dehydrated with acetone $(2 \times 30 \mathrm{~min})$, dried in a critical-point dryer (BALZERS CPD 030), sputter-coated with gold in a BAL-TEC SCD005 and observed in a JEOL JSM-5300 scanning electron microscope (the numbers written on the specimen holder confirmed that the image in the microscope is not inverted). The chirality of each spermatozoon encountered was recorded.

\section{Results}

In all specimens, we found multiple spermatozoa. In all observed spermatozoa, the nucleus (head) carried four or five helically arranged keels starting directly posterior of the acrosome. The nucleus was slender, circa nine times as long as wide: mean width $1.33 \mu \mathrm{m}$ ( $\mathrm{SD} 0.15 \mu \mathrm{m}$; min. $1.04 \mu \mathrm{m}$, max. $1.66 \mu \mathrm{m} ; N=20$ ), mean length $11.7 \mu \mathrm{m}$ (SD $1.17 \mu \mathrm{m}$; min. $10.8 \mu \mathrm{m}$, max. $14.6 \mu \mathrm{m} ; N=9$ ) and itself also spiral, consisting of approximately one loose helical whorl. In the anterior part of the midpiece, a single, coiled glycogen-filled helix compartment was visible,

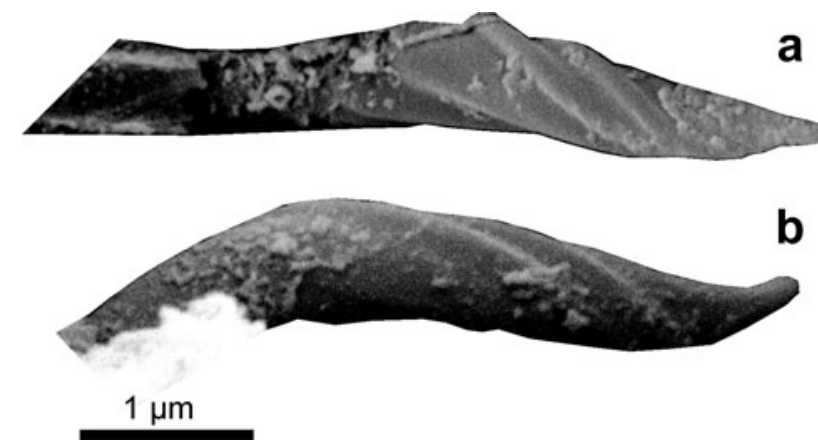

Fig. 3 Amphidromus inversus, scanning electron micrographs of nuclei of spermatozoa from a dextral-bodied (a) and a sinistral-bodied (b) individual. Both nuclei show a dextral coil

which was lacking from the much longer posterior part (mean diameter: $658 \mathrm{~nm}$; SD $59 \mathrm{~nm}$; min. $523 \mathrm{~nm}$; $\max$. $733 \mathrm{~nm} ; N=20$ ) of the midpiece. Since only fragments of the spermatozoa were exposed, we could not determine the full length for entire spermatozoa. For each individual, we examined between 5 and 60 spermatozoa (total spermatozoa examined: 207) and found that the chirality of the nucleus, its helical keels and the glycogen helix was clearly dextral in all cases (Figs. 2a, 3).

\section{Discussion}

The shape and dimensions of the Amphidromus inversus spermatozoon, with its slender, screw-like head and long glycogen helices along the midpiece is similar to the complex, asymmetric spermatozoa reported for other Pulmonata (e.g. Thompson 1973). These spiral arrangements develop during the late stage of spermiogenesis (Watts 1952), initially in the nucleus, then in the midpiece (Hickman 1931), a process apparently aided by a twisted sheath of microtubuli that lies around the mitochondrial derivative (Healy 2001). Unfortunately, only rarely in the rich literature on pulmonate sperm morphology is the coiling direction of the helical elements explicitly mentioned [not even by Thompson (1973), who dwells at length on the functional significance of coiled gastropod spermatozoa], and chirality cannot be determined unambiguously from published transmission electron micrographs, only from scanning electron micrographs. Yet, what is available in the literature is sufficient to state that the chiral uniformity found in A. inversus is not representative for Pulmonata as a whole.

In some species, like in A. inversus, coiling direction of the helical elements of the spermatozoa appears to be consistently dextral, as is the case in the dextral-bodied Arion hortensis Férussac, 1819, Agriolimax reticulatus (Müller, 1774), Milax sowerbyi (Férussac, 1823), Siphonaria 
japonica (Donovan, 1834), S. sirius (Pilsbry, 1894), and Anguispira alternata (Say, 1816) (Anderson 1982; Maxwell 1975; Bayne 1970; Sumikawa and Funakoshi 1984) and in the sinistral-bodied Bulinus globosus (Morelet, 1866), B. africanus (Krauss, 1848), and Physella acuta (Draparnaud, 1805) (Appleton and Brackenbury 1997; Brackenbury and Appleton 1991). In other species, the coiling is sinistral, like in the (dextral-bodied) terrestrial species Cornu aspersum (Müller, 1774), Oxyloma elegans (Risso, 1826) and Testacella Draparnaud, 1801 sp. (Anderson and Personne 1967; Maxwell 1975; Watts 1952; Selmi et al. 1989). In other species, spermatozoon chirality appears to be mixed: whereas Selman and Waddington (1953) describe the nuclear helical ridges and glycogen helices of 12 sperm cells from sinistral-bodied Radix labiata (Rossmässler, 1835) and eight sperm cells from dextral-bodied R. labiata to be all dextral, the scanning electron micrographs of $R$. labiata spermatozoa in Maxwell (1975) show sinistral coils on both the nucleus and the midpiece [as do the splendid freeze-etch electron micrographs of Thompson (1973) for the dextral-bodied L. stagnalis]. Hickman (1931: 265) states that in the dextral-bodied Novisuccinea ovalis (Say, 1817), 'there is no uniformity of direction of the spirals. [...] Out of many specimens examined, I find that the spirals may go in either a left or a right direction from head to tail, and that one condition is about as common as the other' and a similar observation is made for the dextralbodied Arion subfuscus (Draparnaud, 1805) by Watts (1952).

The above-admittedly very limited - review of the literature and our new data for A. inversus show clearly that spermatozoon chirality may be fixed within species, or dimorphic, even within an individual, and that it is not correlated with whole-body chirality in any obvious way. This means that it is unlikely that the cell ultrastructure that gives rise to the helical twists in the developing spermatid has the same origin as the one that sets off chiral development in the embryo. Similarly, it is unlikely that spermatozoon chirality plays a role in the maintenance of wholebody chiral dimorphism in Amphidromus inversus.

Yet, our data do generate new and interesting questions about the evolution and genetics of spermatozoon chirality. First, the fact that chiral dimorphism exists in some species and chiral monomorphism in others suggests that the chirality of components of the cell ultrastructure in early spermatids evolves rapidly and can shift easily between heritable and random orientation. Second, as Thompson (1973), using scale models of gastropod spermatozoa in glycerol, has shown that the helical shape of the nucleus and midpiece provide a means of converting uniplanar flagellar activity into helical forward movement, then swimming and turning behaviour of the active spermatozoa may be influenced by the chirality. In addition, in human sperm, spontaneous alternation behaviour has been recorded, which makes sperm cells, when forced to turn in a maze, preferentially turn in the opposite direction at the first opportunity (Brugger et al. 2002). It is thus not inconceivable that sperm chirality will have an effect on the escape rate of the spermatozoa from the gametolytic organ, on sperm competition and on oocyte penetration.

Acknowledgments We would like to acknowledge the help of John Healy (Queensland Museum, Brisbane, Australia) with the interpretation of the scanning electron micrographs of A. inversus spermatozoa and with finding missing literature. A previous version of this article was read and improved by Joris Koene, John Healy, Rich Palmer, and four anonymous reviewers.

Open Access This article is distributed under the terms of the Creative Commons Attribution Noncommercial License which permits any noncommercial use, distribution, and reproduction in any medium, provided the original author(s) and source are credited.

\section{References}

Anderson WA (1982) An ultrastructural analysis of the mature spermatozoon of Anguispira alternata (Say) (Pulmonata, Stylommatophora). J Morphol 173:249-257

Anderson WA, Personne P (1967) The fine structure of the neck region of spermatozoa of Helix aspersa. J Microsc 6:1033-1042

Appleton CC, Brackenbury TD (1997) A comparative study of the mature spermatozoa of Bulinus africanus (Krauss, 1848) and $B$. globosus (Morelet, 1866) (Gastropoda: Planorbidae). J Moll Stud 63:401-406

Bayne CJ (1970) Organization of the spermatozoon of Agriolimax reticulatus, the grey field slug. Z Zellforsch 103:75-89

Boycott AE, Diver C (1923) On the inheritance of sinistrality in Limnaea peregra. Proc R Soc Lond B 95:207-213

Brackenbury TD, Appleton CC (1991) Morphology of the mature spermatozoon of Physa acuta (Draparnaud, 1801) (Gastropoda: Physidae). J Moll Stud 57:211-218

Brown NA, Wolpert L (1990) The development of handedness in left/right asymmetry. Development 109:1-9

Brugger P, Macas E, Ihlemann J (2002) Do sperm cells remember? Behav Brain Res 136:325-328

Gittenberger E (1988) Sympatric speciation in snails: a largely neglected model. Evolution 42:826-828

Grande C, Patel NH (2008) Nodal signalling is involved in left-right asymmetry in snails. Nature 457:1007-1011

Harada Y, Hosoiri Y, Kuroda R (2004) Isolation and evaluation of dextral-specific and dextral-enriched cDNA clones as candidates for the handedness-determining gene in a freshwater gastropod, Lymnaea stagnalis. Dev Genes Evol 214:159-169

Healy JM (1988) Sperm morphology and its systematic importance in the Gastropoda. Malac Rev Suppl 4:251-266

Healy JM (2001) Spermatogenesis and oogenesis. In: Barker GM (ed) The biology of terrestrial mollusks. CABI Publishing, Wallingford, pp 357-382

Hickman CP (1931) The spermiogenesis of Succinea ovalis Say, with special reference to the components of the sperm. J Morphol Physiol 51:243-289

Hirokawa N, Tanaka Y, Okada Y, Takeda S (2006) Nodal flow and the generation of left-right asymmetry. Cell 125:33-45 
Ishijima S, Hamaguchi Y (1993) Calcium ion regulation of chirality of beating flagellum of reactivated sea urchin spermatozoa. Biophys J 65:1445-1448

Ishijima S, Ishijima SA, Afzelius BA (1999) Movement of Turritella spermatozoa: direction of propagation and chirality of flagellar bends. Cell Motil Cytoskeleton 44:85-95

Kuroda R, Endo B, Abe M, Shimizu M (2009) Chiral blastomere arrangement dictates zygotic left-right asymmetry pathway in snails. Nature 462:790-794

Maxwell WL (1975) Scanning electron microscope studies of Pulmonate spermatozoa. Veliger 18:31-33

Palmer AR (2004) Symmetry breaking and the evolution of development. Science 306:828-833

Schilthuizen M, Davison A (2005) The convoluted evolution of snail chirality. Naturwissenschaften 11:504-515

Schilthuizen M, Looijestijn S (2009) The sexology of the chirally dimorphic snail species Amphidromus inversus. Malacologia 51:379-387

Schilthuizen M, Craze PG, Cabanban AS, Davison A, Stone J, Gittenberger E, Scott BJ (2007) Sexual selection maintains whole-body chiral dimorphism in snails. J Evol Biol 20:1941-1949
Selman GG, Waddington CH (1953) The structure of the spermatozoa in dextral and sinistral races of Limnaea peregra. Q J Microsc Sci 94:391-397

Selmi MG, Bigliardi E, Giusti F (1989) Morphological modifications in stored heterospermatozoa of Oxyloma elegans (Pulmonata: Stylommatophora). J Ultrastruct Mol Struct Res 102:82-86

Shibazaki Y, Shimizu M, Kuroda R (2004) Body handedness is directed by genetically determined cytoskeletal dynamics in the early embryo. Curr Biol 14:1462-1467

Sturtevant AH (1923) Inheritance of direction of coiling in Limnaea. Science 58:269-270

Sumikawa S, Funakoshi C (1984) The fine structure of mature spermatozoa in two species of the Siphonariidae (Pulmonata: Basommatophora). Venus 43:143-155

Thompson TE (1973) Euthyneuran and other molluscan spermatozoa. Malacologia 14:167-206 plus addendum 443-444

Ueshima R, Asami T (2003) Single-gene speciation by left-right reversal. Nature 425:679

Watts AHG (1952) Spermatogenesis in the slug, Arion subfuscus. J Morphol 91:53-78 